\title{
AVALIAÇÃO DE GENÓTIPOS DE MILHO PARA SEMEADURA PRECOCE SOB INFLUÊNCIA DE BAIXA TEMPERATURA ${ }^{1}$
}

HELENLÚCIADACRUZ², CIBELEDOS SANTOS FERRARI ${ }^{3}$, GERI EDUARDO MENEGHELLO ${ }^{3}$, VALMOR KONFLANZ ${ }^{3}$, PAULODEJALMAZIMMER ${ }^{4}$, PATRÍCIADASILVA VINHOLES ${ }^{5}$, MARIA ALICE DASILVADE CASTRO ${ }^{6}$

\begin{abstract}
RESUMO - O milho (Zea mays L.) é uma planta de clima tropical que exige calor e umidade para produzir satisfatoriamente e proporcionar rendimentos compensadores. Diversos fatores podem comprometer a germinação das sementes e a emergência de plântulas no campo, merecendo destaque a semeadura em solos com baixas temperaturas. Em regiões que predominam condições de baixas temperaturas, seria importante o uso de sementes mais tolerantes a essa condição de estresse. Sementes de milho apresentam variabilidade genética para a germinação a baixas temperaturas. $\mathrm{O}$ objetivo deste trabalho foi classificar genótipos de milho quanto a tolerância das sementes à baixa temperatura de germinação, identificando àqueles com potencial para utilização em semeadura precoce. Avaliaram-se 16 genótipos provenientes do programa de melhoramento de milho da empresa KSP Sementes e Pesquisas Ltda., sendo 10 linhagens em diferentes estádios endogâmicos, seis populações de fecundação aberta e três híbridos simples comerciais, recomendados para semeadura precoce na Região Sul do Brasil. A avaliação da qualidade fisiológica das sementes foi feita pelos testes de germinação, primeira contagem de germinação, comprimento de plântula, biomassa seca, área foliar e radicular nas temperaturas de $25^{\circ} \mathrm{C} \mathrm{e} 10^{\circ} \mathrm{C}$. Foram realizadas análises eletroforéticas para os sistemas isoenzimáticos da fosfatase ácida, esterase e peroxidase. Os resultados permitiram classificar os genótipos quanto à tolerância das sementes à baixa temperatura, evidenciando que há variabilidade entre eles e potencialidades para serem usados em semeadura precoce na região sul do Brasil.
\end{abstract}

Termos para indexação: Zea mays, baixa temperatura, emergência precoce.

\section{EVALUATION OF CORN GENOTYPES FOR USE IN EARLIER SOWING UNDER LOW TEMPERATURES}

\begin{abstract}
Corn (Zea mays L.) is a characteristic plant of tropical climates that requires heat and humidity to produce satisfactorily and to provide compensatory incomes. Several factors can compromise seed germination and plant emergence in the field, and it is important to consider sowing in soils with low temperatures. In regions where low temperature conditions predominate, the use of more tolerant seeds to this stress condition would be important. Corn seeds present genetic variability for germination at low temperatures. The objective of this study was to classify corn genotypes for germination at low soil temperatures. Sixteen 16 genotypes from the breeding corn program of the company KSP Sementes and Pesquisas Ltda. were evaluated, 10 lines at different endogamic stages, six cross pollination populations and three 3 single commercial hybrids, recommended for earlier sowing in southern Brazil. The physiological quality was evaluated by the tests of germination, first count of germination, plant growth, dry matter, shoot and root area AT $25^{\circ} \mathrm{C}$ and $10^{\circ} \mathrm{C}$. The eletroforetic patterns of the isoenzimatic systems of the acid phosphatase,
\end{abstract}

\footnotetext{
${ }^{1}$ Submetido em 19/12/2005. Aceito para publicação em 20/11/2006.

${ }^{2}$ Bióloga, Discente do Programa de Pós-Graduação em C\&T de Sementes - FAEM/UFPel. helenllc@gmail.com

${ }^{3}$ Eng. Agr., Discente do Programa de Pós-Graduação em C\&T de Sementes - FAEM/UFPel. gmeneghello@gmail.com,ksp@kspsementes.com.br
}

\footnotetext{
${ }^{4}$ Eng. Agr., Dr. Prof. do Departamento de Fitotecnia/FAEM/ UFPel. dejalma@msn.com

${ }^{5}$ Aluna de graduação em Agronomia, Bolsista PIBIC CNPq/UFPel; FAEM/ UFPel.

${ }^{6}$ Técnica em Química, Laboratorista do Departamento de Fitotecnia. FAEM/
} UFPel. 
esterase and peroxydase were also evaluated. The tested materials could be ranked from the results for tolerance to low temperatures, showing that there is variability between them and the possibility of using the best performers in earlier sowings in southern Brazil.

Index terms: Zea mays, low temperature, emergency precocious.

\section{INTRODUÇÃO}

O milho (Zea mays L.) é uma planta de clima tropical que exige calor e umidade para produzir satisfatoriamente e proporcionar rendimentos compensadores (Cultivo do milho, 2005; Duarte, 2005). Assim como a maioria das espécies cultivadas com importância econômica, o milho requer a interação de um conjunto de fatores edafoclimáticos apropriados ao seu bom desenvolvimento (Fancelli e Dourado Neto, 2000).

Apesar do elevado potencial produtivo, o milho apresenta elevada sensibilidade a estresses bióticos e abióticos, fazendo com que o seu cultivo exija um planejamento e um manejo rigoroso, a fim de maximizar a sua capacidade produtiva (Andrade, 1995).

O rendimento de uma lavoura de milho é o resultado do potencial genético da semente e das condições edafoclimáticas do local de semeadura, além do manejo da lavoura. O potencial genético da cultivar é responsável por $50 \%$ do rendimento final. Consequientemente, a escolha de sementes com alta qualidade fisiológica e adaptada às condições locais pode ser a razão de sucesso ou insucesso da lavoura (Sans e Santana, 2005).

Após a semeadura, as sementes absorvem água e iniciam o processo metabólico de germinação. Com a umidade relativa do ar adequada e a temperatura entre 25 e $30^{\circ} \mathrm{C}$ (Fancelli e Dourado Neto, 2000), a emergência ocorre em quatro a cinco dias, porém, em condições de baixa temperatura e pouca umidade, pode demorar até duas semanas (Sans e Santana, 2005). O atraso na emergência pode ser causado por temperaturas médias do ar inferiores a $14^{\circ} \mathrm{C}$ no momento da semeadura (Magalhães e Durães, 2002). Se a temperatura do solo estiver próxima de $10^{\circ} \mathrm{C}$ ou superior a $40^{\circ} \mathrm{C}$, a germinação pode ser prejudicada ou não ocorrer (Sans e Santana, 2005).

Dessa maneira, em semeadura precoce, quando a temperatura do solo tende a ser baixa, principalmente na região sul do Brasil, deve-se levar em consideração um aumento no número de sementes por unidade de área, para evitar a redução no número final de plantas na lavoura. Entretanto, esta prática pode acarretar um aumento nos custos de implantação da lavoura e não garantir um estande adequado e uniforme.
O estabelecimento da época ideal para a semeadura depende da região, do genótipo e das condições ambientais. Portanto, a época de semeadura adequada é aquela em que a cultura é capaz de expressar o máximo de seu potencial genético nas condições edafoclimáticas em questão (Magalhães e Durães, 2002).

Sabe-se que o milho apresenta variabilidade genética para a germinação a baixas temperaturas, sendo assim, é desejável selecionar genótipos que apresentem essa característica e utilizá-los em plantios nessas condições, garantindo vantagem competitiva frente aos demais. A seleção pode ser feita testando diferentes lotes em temperaturas inferiores à recomendada para a cultura. Os genótipos que conseguem gerar plântulas normais nessas condições, possuem vantagem frente aos demais, pois o florescimento ocorre antes dos períodos mais propensos a estiagens e a colheita pode ser realizada ainda na entressafra, possibilitando produtividade satisfatória, mínimo de perdas e a obtenção de preços mais elevados na venda do produto (Santis et al., 1999).

Esse trabalho teve o objetivo de classificar genótipos de milho quanto à tolerância das sementes à baixa temperatura de germinação identificando àqueles com potencial para utilização em semeadura precoce.

\section{MATERIALE MÉTODOS}

O presente trabalho foi desenvolvido no Laboratório Didático de Análise de Sementes pertencente ao Departamento de Fitotecnia da Faculdade de Agronomia Eliseu Maciel, Universidade Federal de Pelotas. Foram utilizados 16 genótipos, denominados G1 a G16, pertencentes ao programa de melhoramento de milho da empresa KSP Sementes e Pesquisas Ltda., sendo G1 a G10 linhagens em diferentes estádios endogâmigos e G11 a G16 populações de polinização aberta, e três híbridos simples comerciais (HC1, HC2 e HC3) recomendados para semeadura precoce para a Região Sul do Brasil, que foram considerados testemunhas.

Conduziram-se dois experimentos concomitantemente. No primeiro ensaio utilizou-se a temperatura de germinação de $25^{\circ} \mathrm{C}$, recomendada para a espécie (Brasil, 1992), e no segundo ensaio, a temperatura de $10^{\circ} \mathrm{C}$. Em ambos os ensaios 
e para todos os genótipos testados as sementes utilizadas não foram submetidas a tratamentos químicos, e não padronizadas quanto ao tamanho.

Para a avaliação da qualidade fisiológica das sementes foram realizados os seguintes testes:

Germinação: realizada com três repetições estatísticas, subdivididas em quatro subamostras de 50 sementes, totalizando 600 sementes que foram semeadas sobre papel germiteste umedecido com água 2,5 vezes o peso do papel. Para o primeiro ensaio foi utilizado o germinador de capela Biomatic e a contagem das plântulas normais, sementes mortas e plântulas anormais foram efetuadas no sétimo dia após a semeadura (Brasil, 1992). No segundo ensaio, a germinação foi conduzida em câmara do tipo BOD e as contagens efetuadas aos 14 dias após a semeadura.

Primeira contagem da germinação: a avaliação da porcentagem de plântulas normais foi realizada no quarto dia após a semeadura (Krzyzanowski et. al, 1999). Esta variável foi avaliada somente para a temperatura de $25^{\circ} \mathrm{C}$, pois na temperatura de $10^{\circ} \mathrm{C}$ o desenvolvimento das plântulas não havia iniciado.

Comprimento de plântula: vinte e cinco plântulas normais, de cada repetição, obtidas de maneira aleatória da contagem final do teste de germinação foram medidas com auxilio de uma régua graduada, obtendo-se os comprimentos da parte aérea, do sistema radicular e o comprimento total da plântula. Para efeito de análise estatística considerou-se o valor médio das plantas analisadas em cada repetição.

Área foliar e radicular: utilizaram-se as mesmas plântulas usadas para a avaliação do comprimento de plântula. Inicialmente as partes aérea e radicular foram separadas e avaliadas individualmente em um medidor de área foliar modelo LI 3100/Área Meter, sendo obtidos valores médios para cada repetição.

Biomassa seca: após avaliação das áreas foliar e radicular, o material foi acondicionado em sacos de papel e secado em estufa com circulação de ar na temperatura de $50^{\circ} \pm 2^{\circ} \mathrm{C}$ até a estabilização do peso, que ocorreu em 48 horas. As amostras foram então colocadas em dessecador contendo sílica para resfriamento e posteriormente pesadas em balança analítica com precisão de três casas decimais (miligrama).

Análise de isoenzimas: foi utilizado o sistema de eletroforese vertical para as análises das isoenzimas esterase, fosfatase ácida e peroxidase. O material vegetal de cada um dos genótipos nas duas temperaturas avaliadas foi composto de 10 plântulas obtidas da contagem final do teste de germinação. As plântulas foram maceradas em gral de porcelana sobre cubos de gelo e $200 \mathrm{mg}$ de cada extrato vegetal foram colocados em tubo eppendorf acrescidos de solução extratora (tampão do gel $+0,15 \%$ de â-mercaptoetanol) na proporção 1:2 (p/v). A eletroforese foi realizada em géis de poliacrilamida $7 \%$, colocando $20 \mu \mathrm{L}$ de cada amostra em canaletas feitas com o auxílio de um pente de acrílico. Os padrões isoenzimáticos foram analisados pela metodologia descrita por Scandalios (1969). Os géis foram colocados em cubas eletroforéticas mantidas em câmara fria com temperatura entre 4 e $6^{\circ} \mathrm{C}$. As migrações eletroforéticas foram realizadas com uma diferença de potencial de $10 \mathrm{~V} . \mathrm{cm}^{-1}$, até que a frente de corrida, formado pelo azul de bromofenol, atingisse $9 \mathrm{~cm}$ do ponto de aplicação. Foram utilizados os sistemas de coloração descritos por Scandalios (1969) e Alfenas (1998). Os géis de eletroforese foram fixados em solução 5:5:1, de água destilada: metanol: ácido acético. A interpretação dos resultados foi baseada na análise visual dos géis de eletroforese, levando em consideração a presença/ ausência, bem como a intensidade de expressão de cada uma das bandas eletroforéticas.

Os resultados dos testes isoenzimáticos foram avaliados apenas visualmente, os demais foram submetidos à análise de variância, com delineamento inteiramente casualizado, com três repetições. A comparação entre as médias foi efetuada pelo teste de Scott-Knott (Scott e Knott, 1974), a 5\% de probabilidade. Os dados expressos em porcentagem foram transformados em arc sen $(\mathrm{x} / 100)^{1 / 2}$ e quando ocorreu valor igual a zero, foram transformados em $(x+0,5)^{1 / 2}$.

\section{RESULTADOS E DISCUSSÃO}

Sementes dos genótipos G2, G11, G12, G13, G15, G16, $\mathrm{HC} 1$ e $\mathrm{HC} 2$ apresentaram desempenho significativamente superior quanto à germinação na temperatura de $10^{\circ} \mathrm{C}$. Esses mesmos genótipos, juntamente com o G14 também apresentaram menor número de plântulas anormais e uma baixa percentagem de sementes mortas. Exceção feita para os genótipos G14 e G16 (Tabela 1). Na temperatura de $25^{\circ} \mathrm{C}$, maiores valores de germinação foram observados em sementes dos genótipos G1, G2, G13, G15, HC1 e HC2. Com relação ao vigor avaliado por meio da primeira contagem do teste de germinação, verificou-se um desempenho superior das sementes dos genótipos G2, G10, G15, G16, HC1 e HC2 (Tabela 1).

A baixa temperatura do solo na semeadura retarda a germinação, diminui a mobilização de reservas e a velocidade de emergência. Além disso, a lentidão na germinação predispõe 
a semente e a plântula a uma menor resistência às condições ambientais adversas, restringe a absorção de nutrientes do solo, bem como ao ataque de patógenos, principalmente fungos do gênero Fusarium, Rhizoctonia, Phytium e Macrophomina (Magalhães e Durães, 2005). Salienta-se que os genótipos G2, G13, G15, HC1 e HC2 apresentaram valores de germinação superiores aos demais em ambas as temperaturas (Tabela 1). Os resultados podem ser atribuídos ao fato de as populações e os híbridos possuem um maior vigor do que as linhagens. Com relação a G2, trata-se de uma linhagem que tem apresentado bom potencial em campo, com elevado vigor.

Observa-se na Tabela 2 que as plântulas dos genótipos G13, G15 e G16 apresentaram maiores pesos de matéria seca da parte aérea à $10^{\circ} \mathrm{C}$. Além desses, os genótipos G1, G2, G3, G11, G12, HC1, HC2 e HC3 foram superiores quanto ao peso da matéria seca do sistema radicular. Com relação ao peso da matéria seca total, os genótipos G2, G11, G12, G13, G14, G15 e G16, juntamente com o híbrido HC1 apresentaram plântulas com maiores acúmulos de biomassa seca. Genótipos que apresentaram melhor desenvolvimento de suas plântulas tendem a ser promissores na utilização em condições de baixas temperaturas.
Com relação ao acúmulo de matéria seca na parte aérea, na temperatura de $25^{\circ} \mathrm{C}$ (Tabela 2), apenas as plântulas do genótipo G15 apresentaram desempenho semelhante ao observado na temperatura de $10^{\circ} \mathrm{C}$. Para biomassa seca do sistema radicular, observou-se que os genótipos G11, G12, G13, G14, G15, G16, HC1 e HC3 foram superiores aos demais, e para biomassa seca total, além dos materiais citados anteriormente, com exceção de G12 e G14, também se destacou o híbrido comercial HC2. É importante mencionar que o genótipo G15 foi o que apresentou melhor desempenho com relação ao acúmulo de matéria seca nas duas temperaturas.

Houve efeito da temperatura sobre o desenvolvimento das plântulas, principalmente no comprimento da parte aérea (Tabela 3), apresentando menores valores na temperatura de $10^{\circ} \mathrm{C}$, corroborando com os estudos realizados por Fancelli e Dourado Neto (2000) e Magalhães e Durães (2002) que observaram retardamento na velocidade de germinação em baixas temperaturas. Os genótipos G13, G14, G15, G16 e HC1 foram os que apresentaram plântulas com maiores comprimentos da parte aérea na temperatura de $10^{\circ} \mathrm{C}$ e os genótipos $\mathrm{G} 2, \mathrm{G} 15$ e $\mathrm{HC} 1$, à $25^{\circ} \mathrm{C}$. Com relação ao comprimento do sistema radicular, os genótipos com maiores

TABELA 1. Germinação, plântulas anormais, sementes mortas e primeira contagem do teste de germinação (1ª̂CTG), de sementes de 16 genótipos e três híbridos comerciais de milho. Pelotas, UFPel, agosto de 2005.

\begin{tabular}{|c|c|c|c|c|c|c|c|}
\hline \multirow{2}{*}{ Genótipo } & \multicolumn{2}{|c|}{ Germinação (\%) } & \multicolumn{2}{|c|}{ Plântulas Anormais (\%) } & \multicolumn{2}{|c|}{ Sementes Mortas (\%) } & \multirow{2}{*}{$\begin{array}{c}1^{\circ} \mathrm{CTG}(\%) \\
25^{\circ} \mathrm{C}\end{array}$} \\
\hline & $10^{\circ} \mathrm{C}^{*}$ & $25^{\circ} \mathrm{C} * *$ & $10^{\circ} \mathrm{C}$ & $25^{\circ} \mathrm{C}$ & $10^{\circ} \mathrm{C}$ & $25^{\circ} \mathrm{C}$ & \\
\hline G1 & $63 \mathrm{~b}$ & $97 \mathrm{a}$ & $29 \mathrm{~b}$ & $1 \mathrm{e}$ & $8 \mathrm{~b}$ & $2 \mathrm{c}$ & $43 \mathrm{e}$ \\
\hline $\mathrm{G} 2$ & $83 \mathrm{a}$ & $95 \mathrm{a}$ & $7 \mathrm{c}$ & $3 \mathrm{e}$ & $10 \mathrm{~b}$ & $2 \mathrm{c}$ & $68 \mathrm{c}$ \\
\hline G3 & $60 \mathrm{~b}$ & $85 \mathrm{c}$ & $28 \mathrm{~b}$ & $11 \mathrm{~d}$ & $12 \mathrm{a}$ & $5 \mathrm{~b}$ & $52 \mathrm{~d}$ \\
\hline G4 & $61 \mathrm{~b}$ & $76 \mathrm{~d}$ & $31 \mathrm{~b}$ & $20 \mathrm{c}$ & $8 \mathrm{~b}$ & $4 b$ & $40 \mathrm{e}$ \\
\hline G5 & $24 \mathrm{c}$ & $17 \mathrm{f}$ & $55 \mathrm{a}$ & $69 \mathrm{a}$ & $21 \mathrm{a}$ & $14 \mathrm{a}$ & $10 \mathrm{~h}$ \\
\hline G6 & $12 \mathrm{c}$ & $72 \mathrm{~d}$ & $73 \mathrm{a}$ & $20 \mathrm{c}$ & $15 \mathrm{a}$ & $7 \mathrm{~b}$ & $62 c$ \\
\hline G7 & $31 \mathrm{c}$ & $39 \mathrm{e}$ & $58 \mathrm{a}$ & $49 \mathrm{~b}$ & $11 \mathrm{a}$ & $13 \mathrm{a}$ & $28 \mathrm{~g}$ \\
\hline G8 & $20 \mathrm{c}$ & $73 \mathrm{~d}$ & $79 \mathrm{a}$ & $25 \mathrm{c}$ & $1 \mathrm{~b}$ & $2 c$ & $25 \mathrm{~g}$ \\
\hline G9 & $36 \mathrm{c}$ & $88 \mathrm{c}$ & $58 \mathrm{a}$ & $10 \mathrm{~d}$ & $6 \mathrm{~b}$ & $3 c$ & $32 \mathrm{f}$ \\
\hline G10 & $60 \mathrm{~b}$ & $88 \mathrm{c}$ & $38 \mathrm{~b}$ & $7 \mathrm{~d}$ & $2 b$ & $2 c$ & $65 \mathrm{c}$ \\
\hline G11 & $90 \mathrm{a}$ & $89 \mathrm{~b}$ & $6 \mathrm{c}$ & $29 \mathrm{c}$ & $4 \mathrm{~b}$ & $4 \mathrm{c}$ & $22 \mathrm{~g}$ \\
\hline G12 & $94 \mathrm{a}$ & $68 \mathrm{~d}$ & $4 \mathrm{c}$ & $3 \mathrm{e}$ & $2 \mathrm{~b}$ & $5 \mathrm{~b}$ & $23 \mathrm{~g}$ \\
\hline G13 & $91 \mathrm{a}$ & $97 \mathrm{a}$ & $9 \mathrm{c}$ & $11 \mathrm{~d}$ & $0 \mathrm{~b}$ & $0 \mathrm{c}$ & $26 \mathrm{~g}$ \\
\hline G14 & $76 b$ & $82 \mathrm{c}$ & $10 \mathrm{c}$ & $3 \mathrm{e}$ & $14 \mathrm{a}$ & $7 \mathrm{~b}$ & $43 \mathrm{e}$ \\
\hline G15 & $83 \mathrm{a}$ & $97 \mathrm{a}$ & $17 \mathrm{c}$ & $12 \mathrm{~d}$ & $0 \mathrm{~b}$ & $0 \mathrm{c}$ & $81 \mathrm{~b}$ \\
\hline G16 & $83 \mathrm{a}$ & $82 \mathrm{c}$ & $4 \mathrm{c}$ & $1 \mathrm{e}$ & $13 \mathrm{a}$ & $7 \mathrm{~b}$ & $68 \mathrm{c}$ \\
\hline $\mathrm{HC} 1$ & $96 \mathrm{a}$ & $98 \mathrm{a}$ & $3 \mathrm{c}$ & $3 \mathrm{e}$ & $1 \mathrm{~b}$ & $1 \mathrm{c}$ & $64 \mathrm{c}$ \\
\hline $\mathrm{HC} 2$ & $97 \mathrm{a}$ & $96 \mathrm{a}$ & $9 \mathrm{c}$ & $6 \mathrm{~d}$ & $0 \mathrm{~b}$ & $1 \mathrm{c}$ & $96 \mathrm{a}$ \\
\hline $\mathrm{HC} 3$ & $74 \mathrm{~b}$ & $90 \mathrm{~b}$ & $21 \mathrm{~b}$ & $12 \mathrm{~d}$ & $5 b$ & $4 c$ & $22 \mathrm{~g}$ \\
\hline
\end{tabular}

Médias seguidas de mesma letra na coluna, não diferem entre si pelo teste Scott-Knott a 5\% de probabilidade.

* Avaliação realizada 14 dias após a semeadura; ** Avaliação realizada 7 dias após a semeadura. 
TABELA 2. Biomassa seca (g) da parte aérea (PMSPA), do sistema radicular (PMSSR) e total (PMST) em mg.pl-1 das plântulas de milho na germinação a 10 e $25^{\circ} \mathrm{C}$.

\begin{tabular}{|c|c|c|c|c|c|c|}
\hline \multirow{2}{*}{ Genótipo } & \multicolumn{2}{|c|}{ PMSPA } & \multicolumn{2}{|c|}{ PMSSR } & \multicolumn{2}{|c|}{ PMST } \\
\hline & $10^{\circ} \mathrm{C}^{*}$ & $25^{\circ} \mathrm{C}^{*}$ & $10^{\circ} \mathrm{C}$ & $25^{\circ} \mathrm{C}$ & $10^{\circ} \mathrm{C}$ & $25^{\circ} \mathrm{C}$ \\
\hline G1 & $6,26 \mathrm{c}$ & $28,44 \mathrm{c}$ & $17,08 \mathrm{a}$ & $12,15 \mathrm{~b}$ & $18.41 \mathrm{~b}$ & $45.52 \mathrm{~b}$ \\
\hline G2 & $22,85 \mathrm{~b}$ & $21,77 \mathrm{c}$ & $20,91 \mathrm{a}$ & $11,42 \mathrm{~b}$ & $34.29 \mathrm{a}$ & $42.68 \mathrm{c}$ \\
\hline G3 & $8,20 \mathrm{c}$ & $26,49 \mathrm{c}$ & $18,98 \mathrm{a}$ & $14,04 \mathrm{~b}$ & $22.23 \mathrm{~b}$ & $45.47 \mathrm{~b}$ \\
\hline G4 & $9,86 \mathrm{c}$ & $23,97 \mathrm{c}$ & $8,14 \mathrm{~b}$ & $3,69 \mathrm{~b}$ & $13.55 \mathrm{~b}$ & $32.12 \mathrm{c}$ \\
\hline G5 & $9,35 \mathrm{c}$ & $8,10 \mathrm{e}$ & $7,37 \mathrm{~b}$ & $13,50 \mathrm{~b}$ & $22.86 \mathrm{~b}$ & $15.46 \mathrm{~d}$ \\
\hline G6 & $5,49 \mathrm{c}$ & $21,08 \mathrm{c}$ & $10,58 \mathrm{~b}$ & $4,90 \mathrm{~b}$ & $10.39 \mathrm{~b}$ & $31.66 \mathrm{c}$ \\
\hline G7 & $6,13 \mathrm{c}$ & $16,57 \mathrm{~d}$ & $5,11 \mathrm{~b}$ & $4,02 \mathrm{~b}$ & $10.14 \mathrm{~b}$ & $21.67 \mathrm{~d}$ \\
\hline G8 & $3,37 \mathrm{c}$ & $22,07 \mathrm{c}$ & $14,67 \mathrm{~b}$ & $8,88 \mathrm{~b}$ & $12.26 \mathrm{~b}$ & $36.74 \mathrm{c}$ \\
\hline G9 & $5,21 \mathrm{c}$ & $24,46 \mathrm{c}$ & $12,42 \mathrm{~b}$ & $13,9 \mathrm{~b}$ & $19.17 \mathrm{~b}$ & $36.87 \mathrm{c}$ \\
\hline G10 & $6,34 \mathrm{c}$ & $24,76 \mathrm{c}$ & $9,10 \mathrm{~b}$ & $6,88 \mathrm{~b}$ & $13.22 \mathrm{~b}$ & $33.85 \mathrm{c}$ \\
\hline G11 & $21,38 \mathrm{~b}$ & $37,58 \mathrm{a}$ & $19,22 \mathrm{a}$ & $25,63 \mathrm{a}$ & $47.01 \mathrm{a}$ & $56.78 \mathrm{a}$ \\
\hline G12 & $21,12 \mathrm{~b}$ & $19,54 \mathrm{c}$ & $15,58 \mathrm{a}$ & $23,39 \mathrm{a}$ & $44.52 \mathrm{a}$ & $35.11 \mathrm{c}$ \\
\hline G13 & $27,75 \mathrm{a}$ & $33,19 \mathrm{~b}$ & $22,40 \mathrm{a}$ & $21,89 \mathrm{a}$ & $49.63 \mathrm{a}$ & $55.59 \mathrm{a}$ \\
\hline G14 & $24,29 \mathrm{~b}$ & $36,8 \mathrm{a}$ & $13,36 \mathrm{~b}$ & $17,63 \mathrm{a}$ & $41.93 \mathrm{a}$ & $50.15 \mathrm{~b}$ \\
\hline G15 & $35,67 \mathrm{a}$ & $40,42 \mathrm{a}$ & $22,90 \mathrm{a}$ & $17,51 \mathrm{a}$ & $53.19 \mathrm{a}$ & $63.33 \mathrm{a}$ \\
\hline G16 & $29,62 \mathrm{a}$ & $34,49 \mathrm{~b}$ & $22,54 \mathrm{a}$ & $19,78 \mathrm{a}$ & $49.40 \mathrm{a}$ & $57.02 \mathrm{a}$ \\
\hline $\mathrm{HC} 1$ & $19,21 \mathrm{~b}$ & $41,61 \mathrm{a}$ & $26,12 \mathrm{a}$ & $22,61 \mathrm{a}$ & $41.81 \mathrm{a}$ & $67.72 \mathrm{a}$ \\
\hline $\mathrm{HC} 2$ & $13,90 \mathrm{c}$ & $41,69 \mathrm{a}$ & $16,36 \mathrm{a}$ & $11,20 \mathrm{~b}$ & $25.09 \mathrm{~b}$ & $58.04 \mathrm{a}$ \\
\hline $\mathrm{HC} 3$ & $12,24 \mathrm{c}$ & $29,68 \mathrm{~b}$ & $20,74 \mathrm{a}$ & $18,12 \mathrm{a}$ & $30.36 \mathrm{~b}$ & $50.42 b$ \\
\hline
\end{tabular}

Médias seguidas de mesma letra na coluna, não diferem entre si pelo teste Scott-Knott a 5\% de probabilidade.

* Avaliação realizada 14 dias após a semeadura; ** Avaliação realizada 7 dias após a semeadura.

TABELA 3. Comprimento da parte aérea (CPA), do sistema radicular (CSR) e total (CT) em cm.pl ${ }^{-1}$ das plântulas de milho, na germinação a temperaturas de 10 e $25^{\circ} \mathrm{C}$.

\begin{tabular}{|c|c|c|c|c|c|c|}
\hline \multirow{2}{*}{ Genótipo } & \multicolumn{2}{|c|}{ CPA } & \multicolumn{2}{|c|}{ CSR } & \multicolumn{2}{|c|}{ CT } \\
\hline & $10^{\circ} \mathrm{C}^{*}$ & $25^{\circ} \mathrm{C}^{*}$ & $10^{\circ} \mathrm{C}$ & $25^{\circ} \mathrm{C}$ & $10^{\circ} \mathrm{C}$ & $25^{\circ} \mathrm{C}$ \\
\hline G1 & $2,27 \mathrm{~d}$ & $12,88 \mathrm{c}$ & $6,17 \mathrm{c}$ & $13,41 \mathrm{a}$ & $8,45 \mathrm{c}$ & $26,29 \mathrm{c}$ \\
\hline G2 & $3,76 \mathrm{c}$ & $14,89 \mathrm{~b}$ & $8,30 \mathrm{c}$ & $14,99 \mathrm{a}$ & $12,06 \mathrm{c}$ & $29,89 \mathrm{~b}$ \\
\hline G3 & $2,75 \mathrm{~d}$ & $10,76 \mathrm{~d}$ & $6,50 \mathrm{c}$ & $12,21 \mathrm{~b}$ & $9,25 \mathrm{c}$ & $22,98 \mathrm{~d}$ \\
\hline G4 & $3,17 \mathrm{~d}$ & $9,77 \mathrm{~d}$ & $4,09 \mathrm{~d}$ & $7,62 \mathrm{~d}$ & $7,26 \mathrm{~d}$ & $17,40 \mathrm{f}$ \\
\hline G5 & $2,53 \mathrm{~d}$ & $5,17 \mathrm{f}$ & $4,50 \mathrm{~d}$ & $5,99 \mathrm{e}$ & $7,03 \mathrm{~d}$ & $11,17 \mathrm{~h}$ \\
\hline G6 & $1,53 \mathrm{~d}$ & $9,46 \mathrm{~d}$ & $4,26 \mathrm{~d}$ & $10,72 \mathrm{~b}$ & $5,79 \mathrm{~d}$ & $20,18 \mathrm{e}$ \\
\hline G7 & $1,57 \mathrm{~d}$ & $7,04 \mathrm{e}$ & $3,86 \mathrm{~d}$ & $6,73 \mathrm{~d}$ & $5,43 \mathrm{~d}$ & $13,77 \mathrm{~g}$ \\
\hline G8 & $1,02 \mathrm{~d}$ & $7,22 \mathrm{e}$ & $4,08 \mathrm{~d}$ & $4,75 \mathrm{e}$ & $5,09 \mathrm{~d}$ & $11,96 \mathrm{~h}$ \\
\hline G9 & $1,35 \mathrm{~d}$ & $6,79 \mathrm{e}$ & $4,61 \mathrm{~d}$ & $7,23 \mathrm{~d}$ & $5,95 \mathrm{~d}$ & $14,01 \mathrm{~g}$ \\
\hline G10 & $1,91 \mathrm{~d}$ & $10,61 \mathrm{~d}$ & $5,82 \mathrm{c}$ & $9,78 \mathrm{c}$ & $7,73 \mathrm{~d}$ & $20,39 \mathrm{e}$ \\
\hline G11 & $5,12 \mathrm{c}$ & $10,10 \mathrm{~d}$ & $9,50 \mathrm{~b}$ & $8,98 \mathrm{c}$ & $14,62 \mathrm{~b}$ & $19,06 \mathrm{f}$ \\
\hline G12 & $5,16 \mathrm{c}$ & $6,67 \mathrm{e}$ & $11,56 \mathrm{~b}$ & $6,67 \mathrm{~d}$ & $16,72 \mathrm{~b}$ & $13,34 \mathrm{~g}$ \\
\hline G13 & $6,74 \mathrm{~b}$ & $10,04 \mathrm{~d}$ & $12,31 \mathrm{a}$ & $10,12 \mathrm{c}$ & $19,05 \mathrm{~b}$ & $20,17 \mathrm{e}$ \\
\hline G14 & $8,10 \mathrm{~b}$ & $13,67 \mathrm{c}$ & $11,46 \mathrm{~b}$ & $11,17 \mathrm{~b}$ & $19,55 \mathrm{~b}$ & $24,83 \mathrm{~d}$ \\
\hline G15 & $9,65 \mathrm{a}$ & $14,41 \mathrm{~b}$ & $14,48 \mathrm{a}$ & $14,69 \mathrm{a}$ & $24,13 \mathrm{a}$ & $29,09 \mathrm{~b}$ \\
\hline G16 & $11,48 \mathrm{a}$ & $13,47 \mathrm{c}$ & $13,06 \mathrm{a}$ & $13,91 \mathrm{a}$ & $24,54 \mathrm{a}$ & $27,39 \mathrm{c}$ \\
\hline $\mathrm{HCl}$ & $6,75 \mathrm{~b}$ & $17,76 \mathrm{a}$ & $11,22 \mathrm{~b}$ & $14,07 \mathrm{a}$ & $17,97 \mathrm{~b}$ & $31,83 \mathrm{a}$ \\
\hline $\mathrm{HC} 2$ & $3,93 \mathrm{c}$ & $12,56 \mathrm{c}$ & $6,52 \mathrm{c}$ & $11,72 \mathrm{~b}$ & $10,45 \mathrm{c}$ & $24,28 \mathrm{~d}$ \\
\hline $\mathrm{HC} 3$ & $2,50 \mathrm{~d}$ & $9,58 \mathrm{~d}$ & $7,31 \mathrm{c}$ & $8,70 \mathrm{c}$ & $9,81 \mathrm{c}$ & $18,27 \mathrm{f}$ \\
\hline
\end{tabular}

Médias seguidas de mesma letra na coluna, não diferem entre si pelo teste Scott-Knott a $5 \%$ de probabilidade.

* Avaliação realizada 14 dias após a semeadura; ** Avaliação realizada 7 dias após a semeadura. 
valores na temperatura de $10^{\circ} \mathrm{C}$ foram $\mathrm{G} 11, \mathrm{G} 12, \mathrm{G} 13, \mathrm{G} 14$, $\mathrm{G} 15, \mathrm{G} 16$ e $\mathrm{HC} 1$, e a $25^{\circ} \mathrm{C}$, os genótipos G1, G2, G14, G15, $\mathrm{G} 16, \mathrm{HC} 1$ e $\mathrm{HC} 2$. Analisando o comprimento total, observouse que à $10^{\circ} \mathrm{C}$ os genótipos G11, G12, G13, G14, G15, G16 e $\mathrm{HC} 1$ foram os que apresentaram plântulas com maiores comprimentos. Na temperatura de $25^{\circ} \mathrm{C}$ os genótipos $\mathrm{G} 2$, G15 e $\mathrm{HC} 1$ foram os materiais que apresentaram tamanho da plântula significativamente maior que os demais.

Pela interpretação dos resultados, verifica-se que os genótipos G15 e G16 foram superiores para as três características avaliadas, na temperatura de $10^{\circ} \mathrm{C}$ (Tabela 3 ). No entanto, à $25^{\circ} \mathrm{C}$, somente o $\mathrm{HC} 1$ apresentou esse
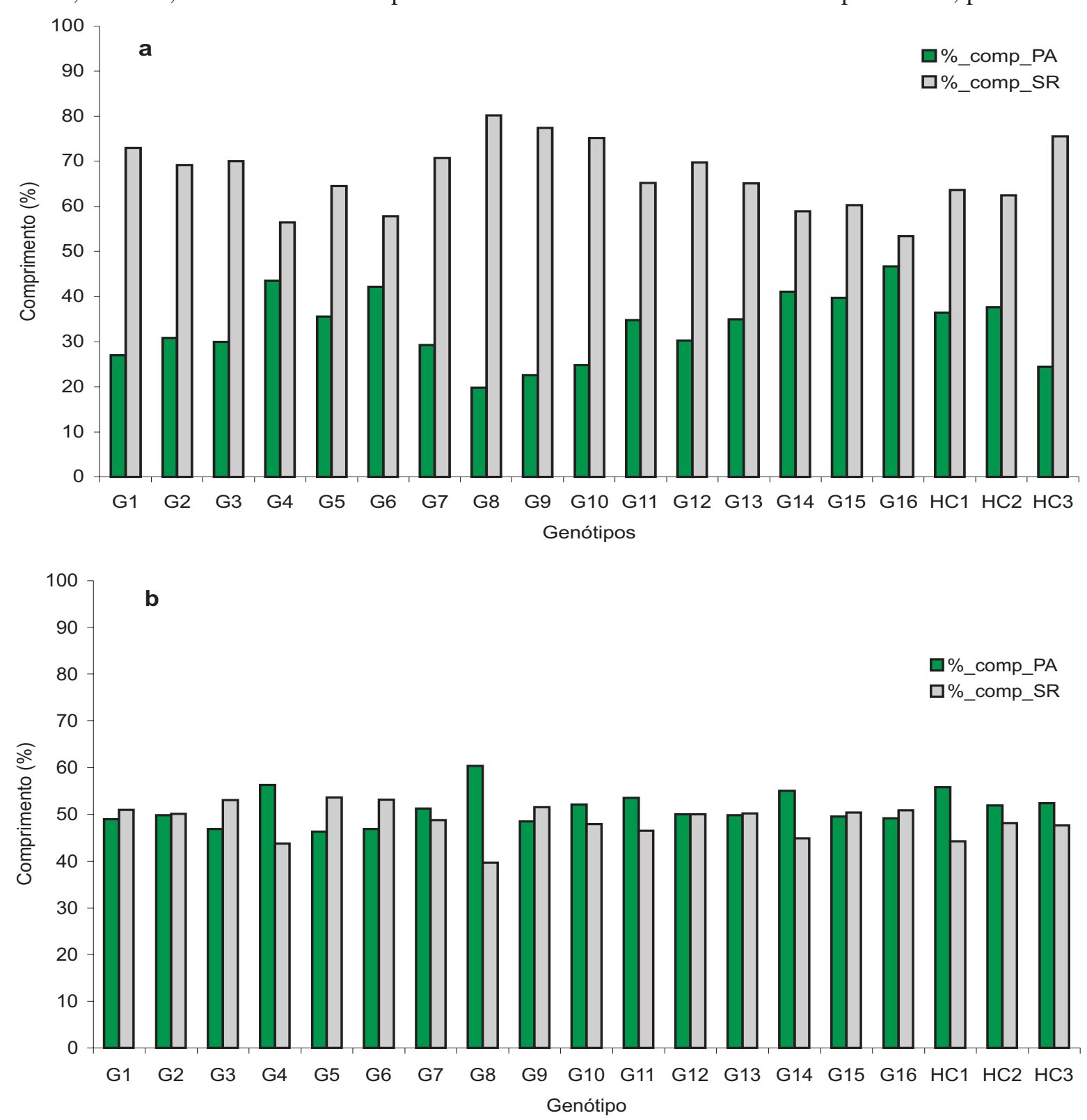

FIGURA 1. Percentual do comprimento da parte aérea e sistema radicular das plântulas de milho nas temperaturas de $10^{\circ} \mathrm{C}(\mathrm{a}) \mathrm{e}$

$25^{\circ}(\mathrm{b})$, aos 14 e 7 dias após a semeadura, respectivamente. comportamento. A temperatura de $10^{\circ} \mathrm{C}$, além de reduzir a germinação das sementes, ocasionou danos às plântulas, o que tem sido denominado "dano de embebição a frio". Assim genótipos menos tolerantes a essa condição de estresse apresentaram plântulas menos vigorosas, a exemplo do G4, G5, G6, G7, G8 e G9, para as três características.

Pode-se observar na Figura 1a, que na temperatura de $10^{\circ} \mathrm{C}$ houve um maior desenvolvimento do sistema radicular em relação à parte aérea, alcançando aproximadamente $2 / 3$ do comprimento total da plântula. Na temperatura recomendada para a cultura, ou seja, $25^{\circ} \mathrm{C}$, o desenvolvimento das raízes foi muito similar ao da parte aérea, pois ambas representam 
aproximadamente $50 \%$ do comprimento total da plântula, conforme pode ser observado na Figura 1b. Avaliando o crescimento de plântulas de milho, Jacob Júnior (2005), observou um maior desenvolvimento do sistema radicular em relação à parte aérea no período de 4 e 8 dias após a semeadura, na temperatura de $25^{\circ} \mathrm{C}$.

Não foram observadas diferenças significativas na área foliar das plântulas dos genótipos, na temperatura de $25^{\circ} \mathrm{C}$ (Tabela 4). Porém para a área radicular as plântulas dos genótipos G15, G16, HC1 e HC3 se destacaram. Os genótipos G15, G16 e HC1 foram os que apresentaram maiores áreas totais das plântulas. $\mathrm{Na}$ temperatura de $10^{\circ} \mathrm{C}$, merecem destaque os genótipos G11, G12, G13, G14, G15, G16 e HC1 que foram superiores em todas as variáveis analisadas.

Analisando o comportamento dos materiais com relação à área foliar, radicular e total, pode-se verificar que o genótipo G12 e G15 foi superiores aos demais na temperatura de $10^{\circ} \mathrm{C}$, podendo ser utilizados em condições de baixas temperaturas.

Diferentemente do observado no comprimento das plântulas à $10^{\circ} \mathrm{C}$, os genótipos G4, G5, G6 e G7 apresentaram área foliar e radicular semelhantes, o mesmo não ocorrendo na temperatura de $25^{\circ} \mathrm{C}$, de um modo geral.

Os padrões isoenzimáticos apresentados a seguir, servem para auxiliar o entendimento da tolerância, dos genótipos avaliados, quando submetidos à germinação em baixa temperatura.

A enzima esterase (EST) está envolvida tanto na hidrólise de ésteres quanto no metabolismo de lipídios. Brandão Junior et al. (1998) observaram a diminuição do número e intensidade de bandas de esterase com a perda da viabilidade das sementes. No entanto, pelos padrões eletroforéticos pode-se observar uma intensidade maior das bandas a $10^{\circ} \mathrm{C}$ do que a $25^{\circ} \mathrm{C}$. Provavelmente isso se deve a um metabolismo mais acelerado em temperaturas ótimas, sugerindo que os materiais de reserva já haviam sido metabolizados aos sete dias da germinação o que provavelmente não ocorreu aos 14 dias, na temperatura de $10^{\circ} \mathrm{C}$. Ressalta-se que os genótipos G11, G12, G13, G14, G15, G16 e $\mathrm{HC} 1$ apresentaram, à $10^{\circ} \mathrm{C}$, menor intensidade de banda que os demais genótipos, concordando com os resultados obtidos na avaliação da qualidade fisiológica das sementes, uma vez essas sementes foram mais vigorosas. (Figura 2a). Este comportamento pode ser de natureza genética e não de qualidade fisiológica, visto que nem todos os genótipos que apresentaram este comportamento mostraram qualidade fisiológica superior, indicando que esta enzima por si só não é indicativo de qualidade fisiológica.

TABELA 4. Área foliar (AF), área radicular (AR) e área total (CT) $\mathrm{em} \mathrm{cm}^{2} \cdot \mathrm{pl}^{-1}$ das plântulas de milho na germinação a temperaturas de 10 e $25^{\circ} \mathrm{C}$.

\begin{tabular}{|c|c|c|c|c|c|c|}
\hline \multirow{2}{*}{ Genótipo } & \multicolumn{2}{|c|}{$\mathrm{AF}$} & \multicolumn{2}{|c|}{ AR } & \multicolumn{2}{|c|}{ AT } \\
\hline & $10^{\circ} \mathrm{C}^{*}$ & $25^{\circ} \mathrm{C}^{*}$ & $10^{\circ} \mathrm{C}$ & $25^{\circ} \mathrm{C}$ & $10^{\circ} \mathrm{C}$ & $25^{\circ} \mathrm{C}$ \\
\hline G1 & $0,79 \mathrm{~b}$ & $3,48 \mathrm{a}$ & $1,77 \mathrm{c}$ & $3,82 \mathrm{~b}$ & $2,56 \mathrm{~b}$ & $7,29 \mathrm{~b}$ \\
\hline $\mathrm{G} 2$ & $1,02 \mathrm{~b}$ & $3,96 \mathrm{a}$ & $2,12 \mathrm{c}$ & $4,57 \mathrm{~b}$ & $3,14 \mathrm{~b}$ & $8,53 \mathrm{a}$ \\
\hline G3 & $0,79 \mathrm{~b}$ & $2,98 \mathrm{a}$ & $1,74 \mathrm{c}$ & $3,81 \mathrm{~b}$ & $2,53 \mathrm{~b}$ & $6,78 \mathrm{~b}$ \\
\hline G4 & $1,02 \mathrm{~b}$ & $2,81 \mathrm{a}$ & $0,95 \mathrm{~d}$ & $2,18 \mathrm{c}$ & $1,97 \mathrm{~b}$ & $4,99 \mathrm{c}$ \\
\hline G5 & $1,25 \mathrm{~b}$ & $2,26 \mathrm{a}$ & $1,46 \mathrm{~d}$ & $2,13 \mathrm{c}$ & $2,72 \mathrm{~b}$ & $4,39 \mathrm{c}$ \\
\hline G6 & $0,83 \mathrm{~b}$ & $2,81 \mathrm{a}$ & $0,89 \mathrm{~d}$ & $2,86 \mathrm{c}$ & $1,72 \mathrm{~b}$ & $5,67 \mathrm{c}$ \\
\hline G7 & $1,22 \mathrm{~b}$ & $2,48 \mathrm{a}$ & $1,33 \mathrm{~d}$ & $2,37 \mathrm{c}$ & $2,55 \mathrm{~b}$ & $4,85 \mathrm{c}$ \\
\hline G8 & $0,84 \mathrm{~b}$ & $2,49 \mathrm{a}$ & $1,85 \mathrm{c}$ & $2,67 \mathrm{c}$ & $2,69 \mathrm{~b}$ & $5,17 \mathrm{c}$ \\
\hline G9 & $0,90 \mathrm{~b}$ & $2,44 \mathrm{a}$ & $1,58 \mathrm{c}$ & $2,58 \mathrm{c}$ & $2,49 \mathrm{~b}$ & $5,02 \mathrm{c}$ \\
\hline G10 & $0,87 \mathrm{~b}$ & $5,14 \mathrm{a}$ & $1,22 \mathrm{~d}$ & $2,14 \mathrm{c}$ & $2,10 \mathrm{~b}$ & $7,27 \mathrm{~b}$ \\
\hline G11 & $1,72 \mathrm{a}$ & $3,52 \mathrm{a}$ & $3,37 \mathrm{~b}$ & $4,26 \mathrm{~b}$ & $5,09 \mathrm{a}$ & $7,78 \mathrm{~b}$ \\
\hline G12 & $1,71 \mathrm{a}$ & $2,38 \mathrm{a}$ & $4,41 \mathrm{a}$ & $3,10 \mathrm{c}$ & $6,13 \mathrm{a}$ & $5,47 \mathrm{c}$ \\
\hline G13 & $2,03 \mathrm{a}$ & $3,22 \mathrm{a}$ & $3,41 \mathrm{~b}$ & $4,45 \mathrm{~b}$ & $5,44 \mathrm{a}$ & $7,66 \mathrm{~b}$ \\
\hline G14 & $2,14 \mathrm{a}$ & $3,55 \mathrm{a}$ & $3,34 \mathrm{~b}$ & $3,90 \mathrm{~b}$ & $5,47 \mathrm{a}$ & $7,45 \mathrm{~b}$ \\
\hline G15 & $2,58 \mathrm{a}$ & $3,58 \mathrm{a}$ & $4,10 \mathrm{a}$ & $6,04 \mathrm{a}$ & $6,68 \mathrm{a}$ & $9,62 \mathrm{a}$ \\
\hline G16 & $2,33 \mathrm{a}$ & $3,18 \mathrm{a}$ & $3,63 \mathrm{~b}$ & $5,94 \mathrm{a}$ & 5,96 a & $9,12 \mathrm{a}$ \\
\hline $\mathrm{HC} 1$ & $1,84 \mathrm{a}$ & $4,50 \mathrm{a}$ & $3,57 \mathrm{~b}$ & $4,97 \mathrm{a}$ & $5,42 \mathrm{a}$ & $9,47 \mathrm{a}$ \\
\hline $\mathrm{HC} 2$ & $1,13 \mathrm{~b}$ & $3,02 \mathrm{a}$ & $1,92 \mathrm{c}$ & $3,45 \mathrm{c}$ & $3,05 \mathrm{~b}$ & $6,47 \mathrm{c}$ \\
\hline HC3 & $1,04 \mathrm{~b}$ & $2,85 \mathrm{a}$ & $2,85 \mathrm{~b}$ & $5,10 \mathrm{a}$ & $3,89 \mathrm{~b}$ & $7,95 \mathrm{~b}$ \\
\hline
\end{tabular}

Médias seguidas de mesma letra na coluna, não diferem entre si pelo teste Scott-Knott a 5\% de probabilidade.

* Avaliação realizada 14 dias após a semeadura; ** Avaliação realizada 7 dias após a semeadura; 
Esterase $10^{\circ} \mathrm{C}$

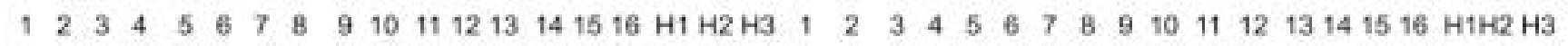

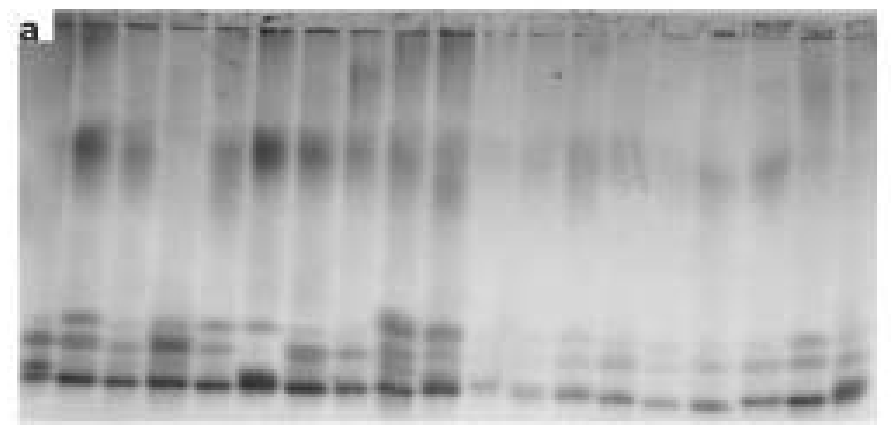

Fosfatase $10^{\circ} \mathrm{C}$

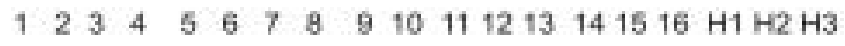

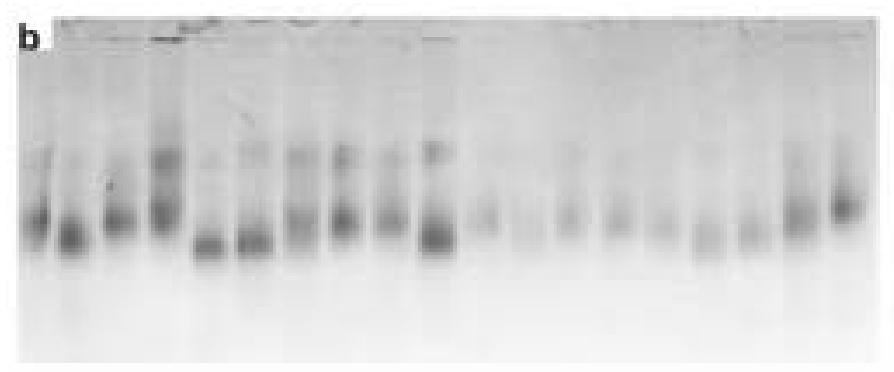

Peroxidase $10^{\circ} \mathrm{C}$

$\begin{array}{lllllllllllllllll}1 & 2 & 3 & 4 & 5 & 6 & 7 & 8 & 9 & 10 & 11 & 12 & 13 & 14 & 1516 & \mathrm{H} 1 \mathrm{H} 2 \mathrm{H} 3\end{array}$

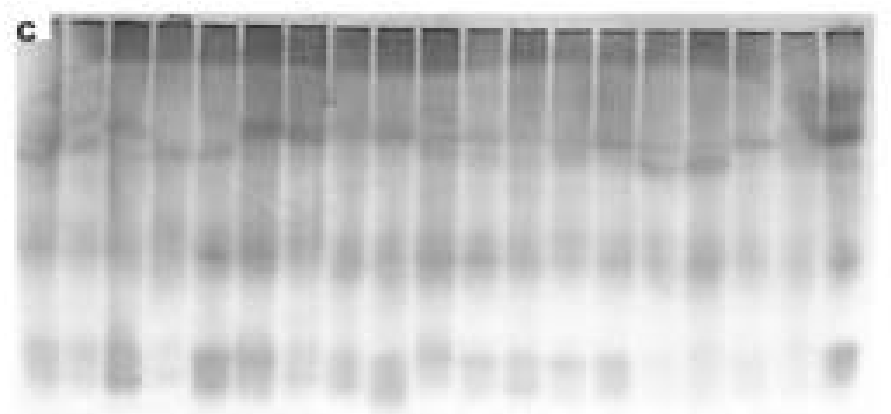

Esterase $\mathbf{2 5}^{\circ} \mathrm{C}$

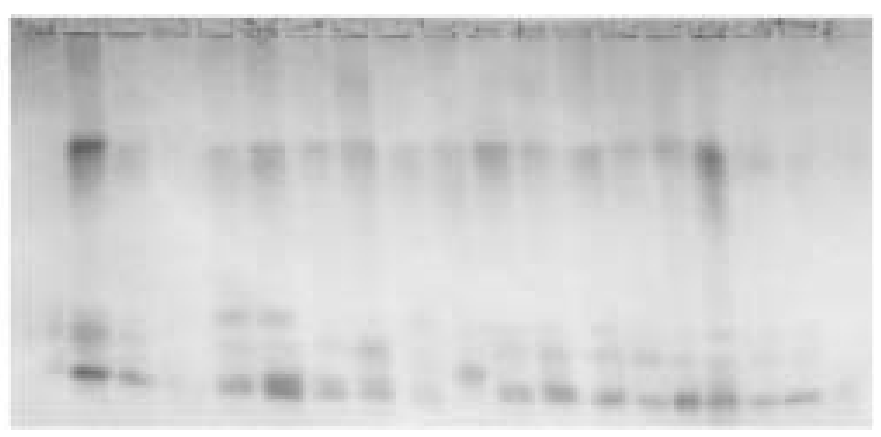

Fosfatase $25^{\circ} \mathrm{C}$
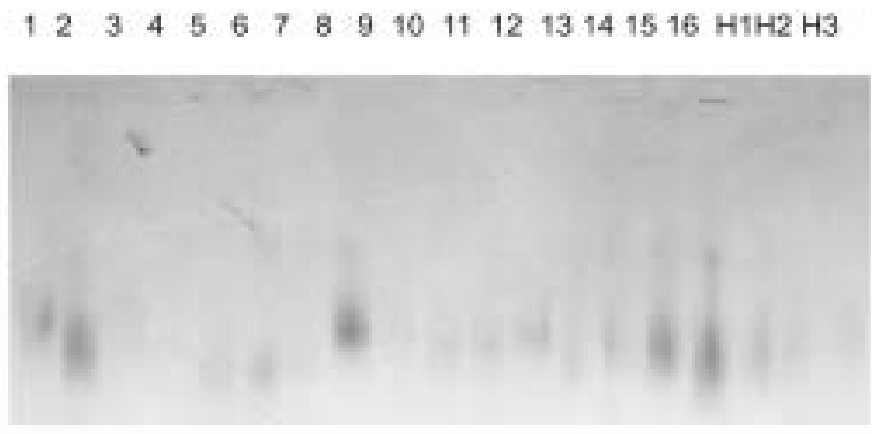

Peroxidase $25^{\circ} \mathrm{C}$

$\begin{array}{lllllllllllllllll}1 & 2 & 3 & 4 & 5 & 6 & 7 & 8 & 9 & 10 & 11 & 12 & 13 & 14 & 15 & 16 & \mathrm{H} 1 \mathrm{H} 2 \mathrm{H} 3\end{array}$

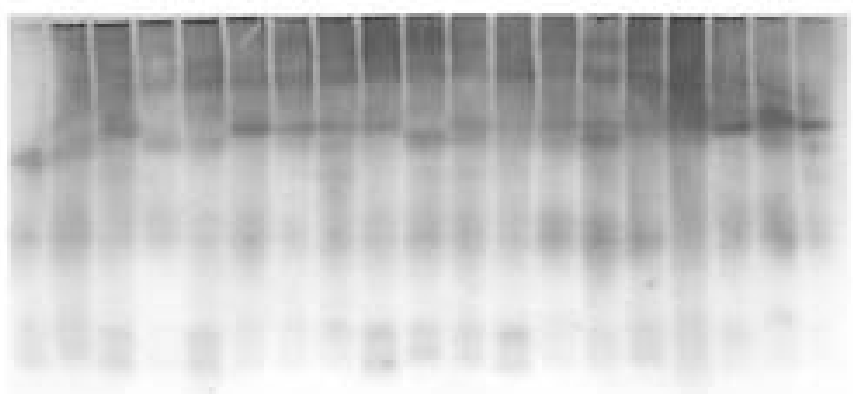

FIGURA 2. Padrão eletroforético da esterase, fosfatase ácida e peroxidase de plântulas de 16 genótipos (1-16) e três híbridos comerciais $(\mathrm{H} 1, \mathrm{H} 2 \mathrm{e} \mathrm{H3})$ de sementes de milho, na germinação a temperaturas de $10^{\circ} \mathrm{e} 25^{\circ} \mathrm{C}$.

A enzima fosfatase ácida (ACP) também apresentou um comportamento similar ao da esterase. Essa enzima participa de reações de hidrólise de ésteres, podendo atuar sobre fosfolipídios de membrana e provocar a peroxidação desses lipídios. Nas membranas mitocondriais, por serem ricas em lipídios insaturados podem apresentar intensa peroxidação desses lipídios, interferindo na respiração. Autores como Brandão Junior (1996) e Vieira (1996) somente verificaram atividade da fosfatase ácida nas sementes de milho e algodão que se apresentavam em avançado grau de deterioração. $\mathrm{Na}$ temperatura de $10^{\circ} \mathrm{C}$, a atividade da fosfatase ácida foi maior, consequentemente maiores danos por embebição e maior peroxidação lipídica podem ter ocorrido. É importante mencionar que as sementes dos genótipos G11, G12, G13, G14, G15, G16 e HC1, também apresentaram menor atividade dessa enzima que os demais genótipos, na temperatura de 
$10^{\circ} \mathrm{C}$ (Figura 2b).

Para o sistema isoenzimático peroxidase (PO), os genótipos apresentaram um comportamento similar nas temperaturas estudadas (Figura 2c). A enzima peroxidase desempenha papel crítico no metabolismo das sementes, por utilização de peróxidos como aceptor de hidrogênio, podendo contribuir para o aumento dos mecanismos de defesa e prevenção de perda na qualidade (Ushimaru et al. 2001).

\section{CONCLUSÕES}

Existe variabilidade entre os genótipos estudados quanto à sensibilidade das sementes à baixa temperatura de germinação.

Os genótipos G11, G12, G13, G14, G15, G16 e HC1 apresentam potencial para serem utilizados em semeadura precoce na região sul do Brasil.

\section{REFERÊNCIAS}

ALFENAS, A.C. Eletroforeses de isoenzimas e proteínas afins: fundamentos e aplicações em plantas e microrganismos. Viçosa: UFV. 1998. 574p.

ANDRADE, F.H. Analysis of growth and yeld of mayze, sunflower and soybean grown at Balcarce, Argentina. Field Crops Research, Amsterdan, v.41, n.1 p.1-12, 1995.

BRANDÃO-JUNIOR, D.S.; CARVALHO, M.L.M.; VIEIRA, M.G.G.C. Variações eletroforéticas de proteínas e isoenzimas relativas à deterioração de sementes de milho envelhecidas artificialmente. Revista Brasileira de Sementes, Brasília, v.21, n.1, p. 114-121, 1999.

BRASIL. Ministério da Agricultura e da Reforma Agrária. Regras para análise de sementes. Brasília: SNDA/DNDV/CLAV, 1992. $365 \mathrm{p}$.

CULTIVO DO MILHO (Zea mays L.). Disponível em: <http:// www.herbário.com.br/dataherb12/milho.html>. Acesso em: 01 ago. 2005.

DUARTE, J.O. Cultivo do Milho - Importância Econômica.
Disponível em: <http://www.cnpms.embrapa.br/publicacoes/ milho/clima.htm. Acesso em: 18 ago. 2005.

FANCELLI, A.L.; DOURADO NETO, D. Ecofisiologia e fenologia. In: FANCELli, A.L.; DOURADO NETO, D. (Ed.) Produção de milho. Guaíba: Agropecuária, 2000. p.21-54

JACOB JUNIOR, E.A. Análise do processo de classificação e da qualidade fisiológica em sementes de milho híbrido. 2005. 40f. Dissertação (Mestrado em Ciência e Tecnologia de Sementes) Faculdade de Agronomia "Eliseu Maciel", Universidade Federal de Pelotas, Pelotas, 2005.

KRZYZANOWSKI, F.C.; VIEIRA, R.D.; FRANÇANETO, J.B. (Ed.) Vigor de sementes: conceitos e testes. Londrina: ABRATES, 1999. p.4.1-4.26.

MAGAlHÃES, P.C.; DURÃES, F.O.M. Cultivo do milho: germinação e emergência. Embrapa Milho e Sorgo, 2002. 9p. (Comunicado técnico).

MAGAlHÃES, P.C.; DURÃES, F.O.M. Cultivo do Milho ecofisiologia. Disponível em: <http://www.cnpms.embrapa.br/ publicacoes/milho/clima.htm> Acesso em: 18 ago. 2005.

SANS, L.M.A.; SANTANA, D.P. Cultivo do Milho - clima e solo. Disponível em: <http://www.cnpms.embrapa.br/publicacoes/ milho/clima.htm> Acesso em: 18 ago. 2005.

SANTIS, A. ; LANGE, P.; GENCHI, G. Changes of mitochondrial properties in maize seedlings associated with selection for germination at low temperature. Fatty acid composition, cytochrome c oxidase, and adenine nucleotide translocase activities. Plant Physiology, Rockville, v.119, n.2, p.743-754, 1999.

SCANDALIOS, J.G. Genetic control of multiple molecular forms of enzymes in plants: a review. Biochemical Genetics, New York, v.3, n.1, p.37-79, 1969.

SCOTT, A.J.; KNOTT, M.A. A cluster analysis method for grouping means in the analysis of variance. Biometrics, Raleigh, v.30, n.2, p.507-512, 1974.

USHIMARU, T.; KANEMATSU, S.; KATAYAMA, M.; TSUJI, H. Antioxicidative enzymes in seedlling of Nelumbo nucifera germinated under water. Physiologia Plantarum, Copenhagen, V.112, n.1, p.39-46, 2001.

VIEIRA, M.G.C.G. Utilização de marcadores moleculares no monitoramento da qualidade sanitária e nível de deterioração de sementes de algodoeiro (Gossypium hirsutum L.). 1996. 127f.. Tese (Doutorado em Fitotecnia) - Universidade Federal de Lavras, Lavras, 1996. 